\title{
Myricetin Apoptotic Effects on T47D Breast Cancer Cells is a P53-Independent Approach
}

\author{
Mitra Soleimani*, Nayereh Sajedi
}

\begin{abstract}
Objective: Using nutraceuticals in cancer therapy is a strategy contributing with other approaches to promote apoptosis in cancer cells. Myricetin is a polyphenol flavonoid that forms main ingredients of various type of foods and beverages. The inducing properties of myricetin in apoptosis is reported by several investigations. The present study aimed to assess apoptotic effects of myricetin on $T 47 D$ breast cancer cells and to evaluate part of the mechanisms of action. Materials and Methods: $T 47 D$ breast cancer cells were assigned into five groups: control (cells in normal condition), myricetin (cells treated with myricetin IC50 concentration) in two different incubation times (24, 48 and 72 hours). MTT assay, annexin v assay, flow cytometry, caspase-3 assay and Real-time PCR were used to evaluate apoptosis in breast cancer cells. Results: The expression rate of apoptotic genes caspase-3, caspase-8, caspase-9, the ratio of $B A X / B c l-2$ as well as the expression of $P 53, B R C A 1, G A D D 45$ genes were increased significantly after treatment of $T 47 D$ breast cancer cells with myricetin. Annexin v assay confirmed significant expression of annexin as were displyed by flow cytometry. Conclusion: Myricetin enhances apoptosis in T47D breast cancer cells by evoking both extrinsic and intrinsic apoptotic pathways. myricetin may practices its apoptotic properties on $T 47 D$ cells through inducing BRCA1- GADD45 pathway.
\end{abstract}

Keywords: Myricetin- flavonoid- T47D- apoptosis

Asian Pac J Cancer Prev, 21 (12), 3697-3704

\section{Introduction}

Breast cancer is the second causes of death and the most prevalent cancer among women in the world (Boulton, 2006). Due to unpleasant side-effects of chemotherapy and their influences on healthy tissues and organs, researchers are trying to find various natural ways to induce apoptosis in cancer cells (Wu et al., 2012). Polyphenols are one of the most abundant natural compounds that are found in plants and flavonoids (Martínez-Pérez, 2016). There are several reports on the role of these compounds in inhibiting the growth of cancer cells. Flavonoids are natural polyphenols constituents with the anticancer properties (Jiao and Dong Zhang, 2016; Ahn et al., 2018). Plants are highly rich in flavonoids as secondary plant metabolites (Weng and Yen, 2012 ). Studies have shown that flavonoids have various biological functions, such as changing epigenetics (Dashwood, 2007; Gilbert and Liu, 2010). They can increase the expression level of tumor suppressor $m R N A s$ and induces apoptosis in the cell (Harkin et al., 1999; Gilbert and Liu, 2010). Myricetin is a flavonol which is found abundantly in nature (Li and Ding, 2012; Shin et al., 2013; Shiomi et al., 2013) with potent antioxidant activities (Erdman, 2006). Use of myricetin as a potent flavonoid in cancer therapy is an understudy approach in treatment of breast cancer.

The role of mutations of tumor suppressor genes in onset and progression of many type of cancers is well recognized (Lee, 1989). Human breast cancer is associated with genetic and epigenetic alterations in a number of tumor suppressors (Perera and Bardeesy, 2012). Mutation in many tumor suppressor genes such as TP53, BRCA1, and $B R C A 2$ involve in the onset and progression of breast cancer (Rice et al., 2000; Dagdemir et al., 2013).

$P 53$ gene is the most commonly mutated gene in several type of human cancers. It is mutated in approximately in $50 \%$ of all cancers. However, the overall frequency of $P 53$ mutation in breast cancer is approximately $20 \%$ (Hollstein et al., 1991).

Unlike other tumor suppressor genes that their mutation lead to their silence or downregulation, the majority alterations in P53 leading to constitutive expression of mutant P53 in cancer cells. This P53 mutations abolishes the function of wild- type P53 but based on the reports, it also aggravates the tumorigenesis. It is believed that mutations in the P53 gene is leading to changes in the conformation of the $\mathrm{p} 53$ protein. This missense mutation lead to accumulation of p53 protein in cells. In other words, mutant P53 contribute to tumorigenesis and mediates survival of the breast cancer cells ( Lim et al., 
2009). In other words, mutatation of the P53 gene, not only suppresses its tumor suppressor functions, but also increases the invasiveness in the cancer cells.

T47-D cell line is an epithelial type breast cancer which is derived for the first time from pleural effusion of an elderly patient. It is specialized with two characteristics: first it contains progesterone receptors that are not controlled by estradiol. Second, it is mutated for P53 but wild type BRCA1 gene (Holliday and Speirs, 2011). The BRCA1 gene (BReast CAncer 1) was the first gene was identified to create potentiality to breast cancer and its mutation was reported abundantly in familial breast cancers (Boulton, 2006; Lee and Muller, 2010). In sporadic breast cancer, its mutation is rare however in nearly $30 \%$ of cases it is downregulated (Yang et al., 2001).

Apoptotic events are categorized into two pathways in which either mitochondria (internal pathway) or death receptors (external pathway) are involved. In the internal pathway, death signals lead to changes in mitochondrial membrane permeability; result in the release of the first set of proapoptotic factors such as cytochrome C. Cytochrome $\mathrm{C}$ binds to and activates Apaf-1 in the cytoplasm (Jiang et al., 2005). Subsequently, Caspase 9 is activated which in turn activates enzymes involved in cell death such as Caspase 3 and DNase (Nagata, 2000; Singh et al., 2007). External pathway is associated with Fas and TNF death receptors. These receptors induce Caspase 8 activity, which is followed by activation of downstream Caspases such as Caspase 3 (Park, 2005).

P53 tumor suppressor gene induces cell apoptosis through both internal and external signaling pathways. BRCA1 induces cell apoptosis in both TP53-dependent and TP53-independent pathways. In TP53-independent pathway, c-Jun N-terminal kinase (JNK) signaling pathway and the GADD45 gene are involved (Fabbro et al., 2004; Ostrakhovitch and Cherian, 2005; Choene et al., 2012; Kim, 2017).

This study set out to investigate the apoptotic effects of myricetin on $T 47 D$ breast cancer cell line that is mutated for P53. Noticing the important roles of the BCL2, BRCA1 and GADD45 genes stated earlier, the expression changes of these genes following treatment with myricetin in the $T 47 D$ cells also aimed to be determined.

To assess the biological effects of myricetin on P53- mutated breast cancer cells, we used the T47D that is a P53- negative breast cancer cell line. We also aimed to investigate part of possible involved mechanism.

\section{Materials and Methods}

\section{Cell culture}

T47-D breast cancer cells were purchased (National Cell Bank, Pasteur Institute of Iran, Tehran) and cultured in DMEM / F12 medium containing 10\% FBS (Sigma, USA) and supplemented with $1 \%$ penicillin and streptomycin (Sigma, USA). Cells incubated for downstream experiments under standard conditions, $37^{\circ} \mathrm{C}$ and $95 \%$ humidity.
MTT assay and determination of myricetin $I C_{50}$

To reach a $100 \mathrm{mmol} / \mathrm{L}$ stock solution of myricetin (Sigma, USA) compound dissolved in DMSO and stored at $-20^{\circ} \mathrm{C}$. The dosage of myricetin that inhibits half maximal proliferation of T47-D cells $\left(\mathrm{IC}_{50}\right)$ (He et al, 2016), were determined as follows: 7,500 cells per well were cultured in 96-well plates and incubated overnight. Cells then were treated with a $200 \mu \mathrm{l}$ serial dilution of myricetin $(175$, $125,100,75,50,25$ and $10 \mu \mathrm{M})$ for 24 hours. Next, to determine the cell viability rate, cells got through MTT assay, using previously described protocol (Ahmadian et al., 2009). Assays included: medium-containing only wells, untreated control cells and test cells treated with myricetin in serial dilutions. MTT $(2 \mathrm{mg} / \mathrm{ml})$ (Sigma, USA) diluted in DMEM-F12 and $20 \mu \mathrm{L}$ of it were added to each well. After incubation for 4 hours at $37^{\circ} \mathrm{C}, 95 \%$ humidity and $5 \% \mathrm{CO}_{2}$, the medium was removed and to dissolve the resulted formazan, $200 \mu \mathrm{L}$ DMSO were added to each well. The absorbance in each well then was measured at $570 \mathrm{~nm}$ wavelength using a microtiter plate reader. The wavelength of $650 \mathrm{~nm}$ was defined as the reference. The blanks were given values close to zero $(+/-0.1) . \mathrm{IC}_{50}$ dosage curve then were drawn. Based on the depicted curve, the concentration of $46 \mu \mathrm{m}$ was considered as myricetin $\mathrm{IC}_{50}$ dosage in this study.

\section{Experimental groups}

T47-D Cells were assigned into four groups: control (cells without treatment), myricetin group; cells treated with $46 \mu \mathrm{m}$ myricetin, that was divided itself into three groups regarding duration of treatment with myricetin (myr24h, myr48h and myr72h). A control group was designated for each time duration and accompanied with it to the end of experiment.

\section{Annexin V staining assay and flow cytometry}

During early apoptosis cell membrane asymmetry is rapidly lost without concomitant loss of membrane integrity. This results in the exposure of phosphatidylserine (PS) at the outer leaflet of the plasma membrane, which serves a physiological role in the recognition and subsequent removal of the dying cell by means of phagocytosis. Annexin V shows high affinity for PS residues in the presence of millimolar concentrations of $\mathrm{Ca}^{2+}$. These apoptotic cells can be distinguished from annexin V-negative living cells using flow cytometric procedure. By simultaneous probing of membrane integrity by staining with the nuclear dye propidium iodide (PI), apoptotic cells can be discriminated from necrotic cells (annexin V/ PI) (Schutte et al., 1998). Annexin V Apoptosis Detection Kit FITC (eBioscience, 88-8005, USA) were used for the assay. Following 24, 48 and 72 hours of treatment with $46 \mu \mathrm{M}$ myricetin, the cells were trypsinized and washed with PBS. After adding the binding buffer, $5 \mu$ l of Annexin V-FITC was treated. Cells were incubated at room temperature for 15 minutes and then washed with washing buffer. Finally, $200 \mu \mathrm{l}$ buffer and $5 \mu \mathrm{l}$ PI (Propidium Iodide) were added to the cells and apoptotic cells were counted by flow cytometry (Becton Dickinson, Heidelberg, Germany). The experiments were performed in triplicate independently at three different 
times.

\section{Real-Time PCR}

The expression level of relevant genes was determined by Real-Time PCR. The cells were treated with $46 \mu \mathrm{M}$ myricetin for 24,48 , and 72 hours. Total RNA in all groups was extracted using the YTA Total RNA Purification Mini kit (Yekta Tajhiz Azma, Iran) according to the manufacturer protocol. After treatment with DNase I to remove genomic DNA, cDNA was reverse transcript using RevertAid TM First Strand cDNA Synthesis Kit (Fermentas). Maxima SYBR Green ROX qPCR Master Mix kit (Fermentas) used according to the manufacturer's protocol in an ABI StepOnePlus ${ }^{\mathrm{TM}}$ Real-Time PCR System (Applied Biosystems). The cycling parameters were as follows: $10 \mathrm{~min}$ at $95^{\circ} \mathrm{C}$ for initial denaturation, followed by 40 cycles of denaturation step at $95^{\circ} \mathrm{C}$ for $15 \mathrm{~s}$ and annealing/ extension for $1 \mathrm{~min}$ at $60^{\circ} \mathrm{C}$. $\beta$-actin was used as a reference gene for internal control. Data were analyzed by Comparative $\mathrm{Ct}(\Delta \Delta \mathrm{ct})$ method. These experiments were carried out in triplicate and were independently repeated at least 3 times. Gene-specific primer sequences for P53, BRCA1, GADD45, BAX, Caspase 3, Caspase 8, Caspase 9, and Bcl-2 are presented in Table 1.

\section{Caspase 3 activity assay}

To evaluate the activity of caspase-3, Fluorometric Assay Kit for Caspase-3/ CPP32 (BioVision, Catalog, and K105-25) was utilized. Caspase-3 is a critical executioner of apoptosis and responsible for the proteolytic cleavage of many key proteins. This assay is a fluorescent assay which detects the activity of caspase- 3 in cell lysates. It contains a fluorogenic substrate (N-Acetyl-Asp-Glu-Val-Asp-7-amino-4-methylcoumarin or Ac-DEVD-AMC or -AFC) for caspase-3. During the assay, activated caspase-3 cleaves this substrate between DEVD and AMC, or AFC, generating highly fluorescent that can be detected using a fluorescence reader with excitation at $380 \mathrm{~nm}$ and emission between $420-460 \mathrm{~nm}$. The more apoptotic cells in the sample, the more Caspase- 3 activity and the more fluorescence emission generated (Ponder and Boise, 2019). The T47-D cells were treated with $46 \mu \mathrm{M}$ myricetin for $24 \mathrm{~h}, 48 \mathrm{~h}$, and 72h. Next, cells were trypsinized and washed with PBS. The pellete of cells suspend in $50 \mu 1$ of chilled Cell Lysis Buffer. Then $50 \mu \mathrm{l}$ of $2 \mathrm{X}$ Reaction Buffer (containing $10 \mathrm{mM}$ DTT) added to each sample. Next, cells were incubated on ice for 10 minutes. Subsequently, $50 \mu \mathrm{L}$ of $2 \mathrm{X}$ reaction buffer, $1 \mu \mathrm{L}$ of DTT $(1 \mathrm{M})$, and $5 \mu \mathrm{L}$ of DEVD-AFC (1 mM) were added to the cell lysates. The reactions were incubated for $2 \mathrm{~h}$ at $37^{\circ} \mathrm{C}, 5 \% \mathrm{CO}_{2}$, and $95 \%$ humidity. Finally, $50 \mu \mathrm{L}$ of cell lysates were transferred in to a 96 well plate and the absorbance was read using a fluorometric spectrophotometer with 400 excitation and 505-nm emission filters. DEVD-AFC emits blue light at $400 \mathrm{~nm}$.

\section{Statistical analysis}

One-way analysis of variance (ANOVA) with Tukey post hoc test was performed using SPSS software package 25.0. to determine statistical significance among different groups. The quantitative data were presented as the mean \pm standard deviation (SD). P-value $<0.01$ was considered as statistically significant level.

\section{Results}

MTT assay and IC50 dose response curve

Approaching the results of MTT assay, a dose response curve for myricetin was depicted and $46 \mu \mathrm{M}$ considered as $\mathrm{IC}_{50}$ (Figure 1).

\section{Cell viability assay}

The results displayed that the viability of the cells decreased significantly following exposure to myricetin

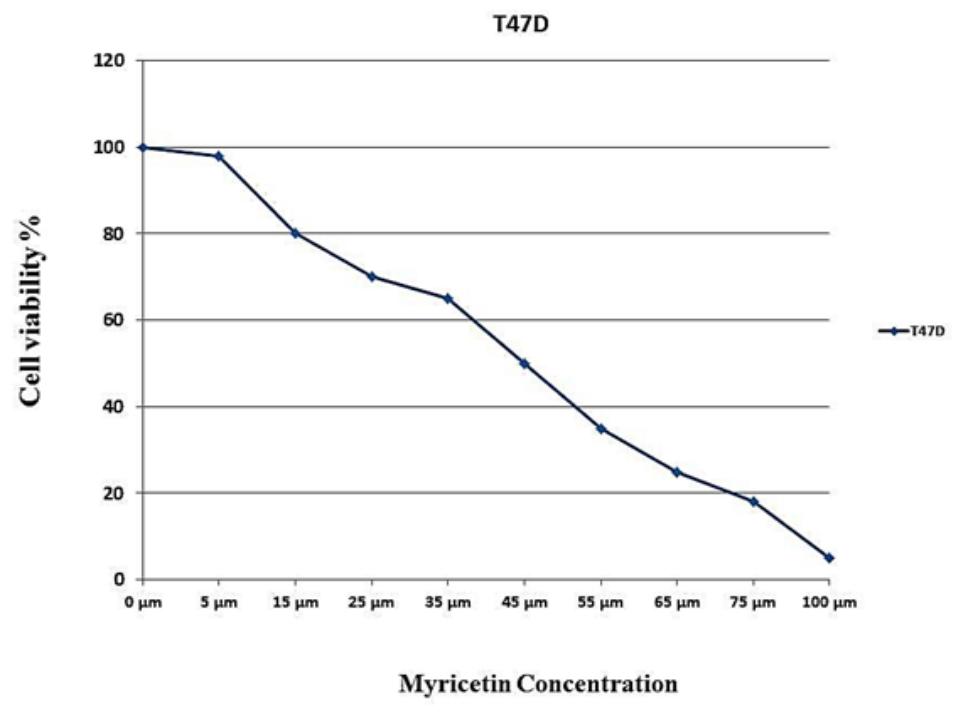

Figure 1. $\mathrm{IC}_{5}$ Assay for Half-Maximal Inhibitory Concentration Analysis of Myricetin in T47-D Cancer Cells after 24 Hours of Treatment. Cells were treated with or without the myricetin in serial dilutions $(175,125,100,75,50,25$ and $10 \mu \mathrm{M}$ ), and the relative amount of viable cells were estimated by measuring the absorbance of the cell suspension after incubation. MTT was carried out and a dose response graph of viability versus myricetin concentration used to calculate $\mathrm{IC}_{50}$ values for T47-D cells. The graph pointed the concentration of $46 \mu \mathrm{M}$ as $\mathrm{IC}_{50}$ for myricetin. 


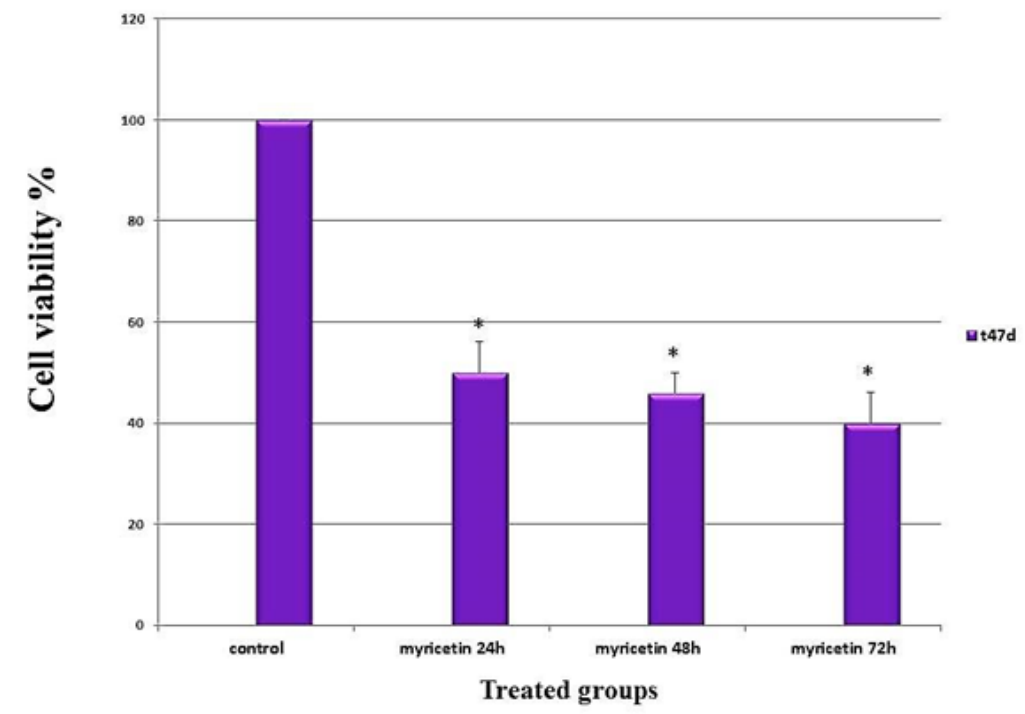

Figure 2. The Viability Assay of the T47-D Breast Cancer Cells Following Treatment with Myricetin as Evaluated by MTT Assay. Cells treated with half maximal inhibition concentration of myricetin $(46 \mu \mathrm{M})$ for 24,48 and 72 hours. The viability of the cells decreased significantly with time. Data is represented as mean $\pm \mathrm{SD}$. $* \mathrm{p}<0.01$.

$(\mathrm{p}<0.01)$. The anti-proliferative effects increased incrementally by time (Figure 2).

\section{Flow cytometry and Annexin v assay}

Flow cytometry was performed to determine the rate of annexin v positive cells. The results showed a significant increase in apoptosis rate in T47-D cells treated with 46 $\mu \mathrm{M}$ myricetin $\mathrm{IC}_{50}$ concentration, $(\mathrm{p}<0.01)$ (Figure 3 ).

\section{Real-time PCR}

The expression level of P53, BRCA1, GADD45, $B A X$, Caspase-3, Caspase-8, Caspase-9, and Bcl-2 was determined by Real-time PCR. The expression level of BRCA1, GADD45, Caspase-3 and BAX genes increased

Table 1. Primers Used in Real-Time PCR

\begin{tabular}{ll}
\hline Primers ID & Primers Sequences \\
\hline Bcl-2 Forward & AAAATACAACATCACAGAGGAAG \\
Bcl-2 Reverse & CTTGATTCTGGTGTTTCCC \\
Caspase 9 Forward & CCTTTGTTCATCTCCTGCTTAG \\
Caspase 9 Reverse & CCTCAAACTCTCAAGAGCACC \\
BRCA1 Forward & TGTTACAAATCACCCCTCAAG \\
BRCA1 Reverse & CCTGATACTTTTCTGGATGCC \\
GADD45 Forward & TTTTGCTGCGAGAACGAC \\
GADD45 Reverse & GAACCCATTGATCCATGTAG \\
Caspase 3 Forward & AGCACTGGAATGACATCTCG \\
Caspase 3 Reverse & ACATCACGCATCAATTCCAC \\
TP53 Forward & CACTCCAGCCACCTGAAGTC \\
TP53 Reverse & GCAAGCAAGGGTTCAAAGAC \\
BAX Forward & GGAGCTGCAGAGGATGATTG \\
BAX Reverse & GTCCAATGTCCAGCCCATG \\
Caspase 8 Forward & ACTGGATGATGACATGAACCTG \\
Caspase 8 Reverse & GCTGAATTCTTCATAGTCGTTG \\
Beta actin Forward & TTCGAGCAAGAGATGGCCA \\
Beta actin Reverse & CACAGGACTCCATGCCCAG \\
\hline
\end{tabular}

significantly after treatment with myricetin. However, the expression level of P53, caspase 8, caspase 9; and Bcl-2 did not show a noticeable change compared to control groups (Figure 4).

\section{Caspase-3 activity assay}

The results showed a significant increase in Caspase-3 activity in the treated groups compared to the control groups. There also were shown that the pick of the caspase- 3 activity was up to 72 hours after treatment with myricetin (Figure 5).

\section{Discussion}

The present study aimed to assess the effect of myricetin, one herbal potent antioxidant, on the apoptosis of T47-D breast cancer cells. Numerous studies have shown that myricetin exert influential effects on malignancies such as breast, colorectal, bladder, lung, skin, and esophageal cancers (Baur and Sinclair, 2006; Zhanget al., 2013; Phillips et al., 2011; Zang et al., 2014; Kim et al., 2014). However, the precise molecular mechanism of myricetin in induction of apoptosis in cancer cells has to be clarified.

It is believed that phytoestrogens, including flavonoids, conducive the reduction in the expression of mutated $P 53$, but promote the expression of the wild-type P53. Phytosterogenes act as the ligands for the ER $\alpha+$ and have different effects. They may be estrogenic or anti-estrogenic. It is reported that in cell lines with mutated P53, flavonoids function as antiestrogenic and reduce the expression of $P 53$ by reducing the expression of $E R \alpha$. Mutated P53 play oncogenic rules and has aggravates in proliferation and prohibition in cnacer cells (Avila et al ., 1994; Takagaki et al., 2005; Saluzzo et al., 2016).

It has been proved that Quercetin, a flavonoid that is a common component of the human diet, mediates the down-regulation of mutant P53 gene in the human 
a
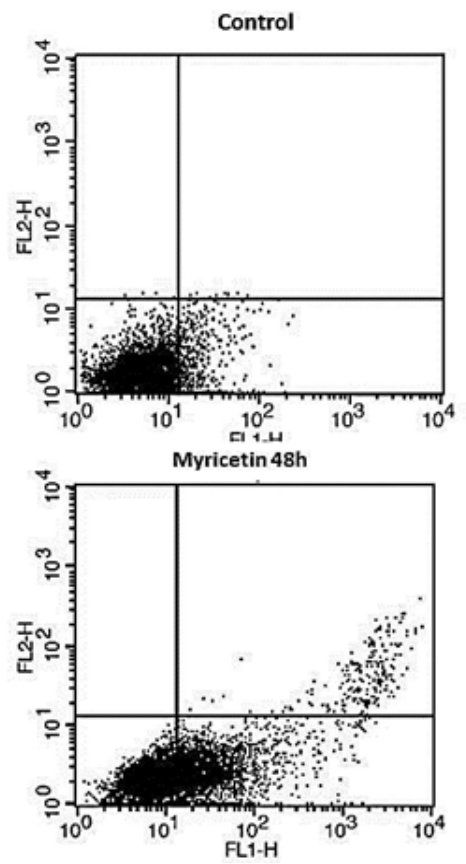
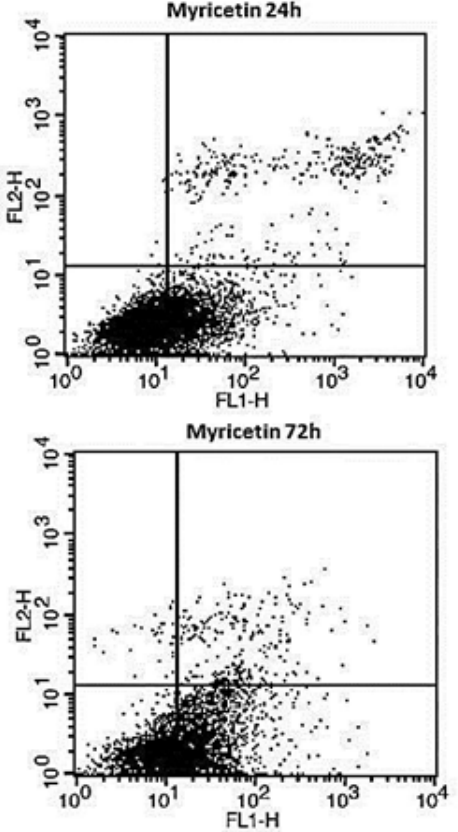

b

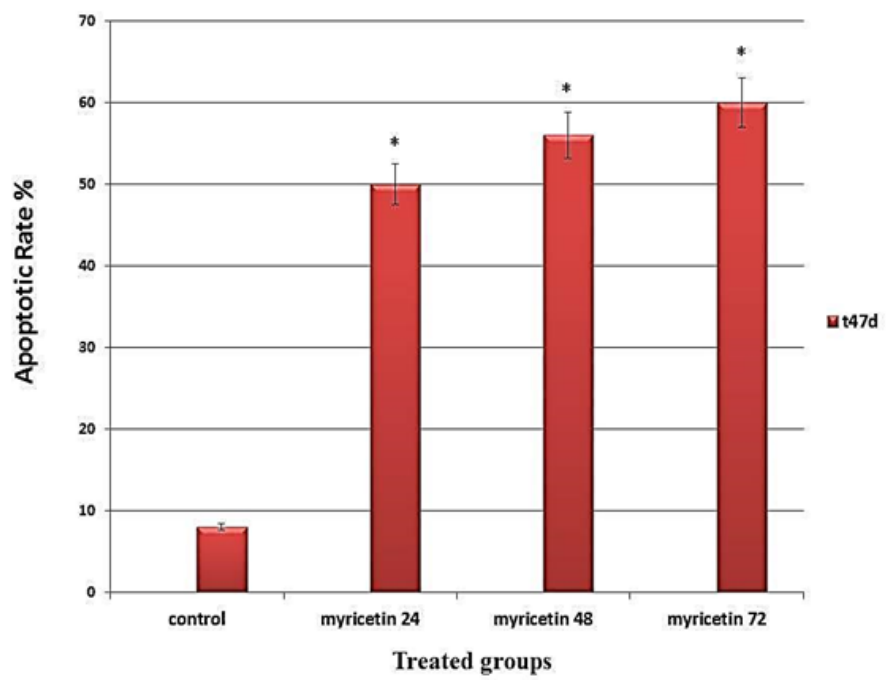

Figure 3. Flow Cytometry Analysis of Myricetin-Induced T47-D Cells. (A) The dot plot diagrams represent typical apoptotic and necrotic cell populations detected by Annexin V-FITC and PI staining. The lower left quadrants of the panels show viable intact cells, which were negative for Annexin V-FITC binding and excluded PI staining (FITC-/PI-); the upper right quadrants show late apoptotic cells, which were positive for Annexin V-FITC binding and PI uptake (FITC+/PI+). The lower right quadrants represent early apoptotic cells, positive for Annexin V-FITC and negative for PI (FITC+/PI-). (B) Bar graph shows average percentage of apoptotic cells. The values are presented as means \pm SD. ${ }^{*} \mathrm{p}<0.01$

breast cancer cell line MDA-MB468. Quercetin did not affect the mRNA levels of P53, but prevented the accumulation of newly synthesized p53 protein (Avila et al., 1994). In our study, considering the steady-state low level gene expression of P53 before and after treatment with myricetin, it is interpreted that the apoptotic effects of myricetin on T47-D cells is being exerted by a mechanism independent of wild-type P53 expression. However, we do not suggest the state of mutant P53 after treatment with myricetin.

According to studies conducted on the effect of myricetin on various cancer cell lines, the genes involved in apoptosis and their expression level highly depend on the type of cell line (Avila et al., 1994; Jiao and Dong
Zhang, 2016; Kim, 2017; Zheng et al., 2017). To assess the biological effects of myricetin on P53- mutated breast cancer cells, we used the T47-D that is a P53- negative breast cancer cell line. Studies on the T47-D cell line are limited and the effect of myricetin on the expression of $B R C A 1$ tumor suppressor gene and GADD45 has not been investigated so far.

P53 is the most commonly mutated gene in several types of human cancers. It is mutated approximately in $50 \%$ of all cancers. However, the overall frequency of $p 53$ mutation in breast cancer is approximately $20 \%$ (Hollstein et al., 1991). Weiss et al., (2010) reported that the deletion of P53 gene in human breast epithelial cells led to the chromosal disability. It is reported that mutant $\mathrm{p} 53$ proteins 
T47D

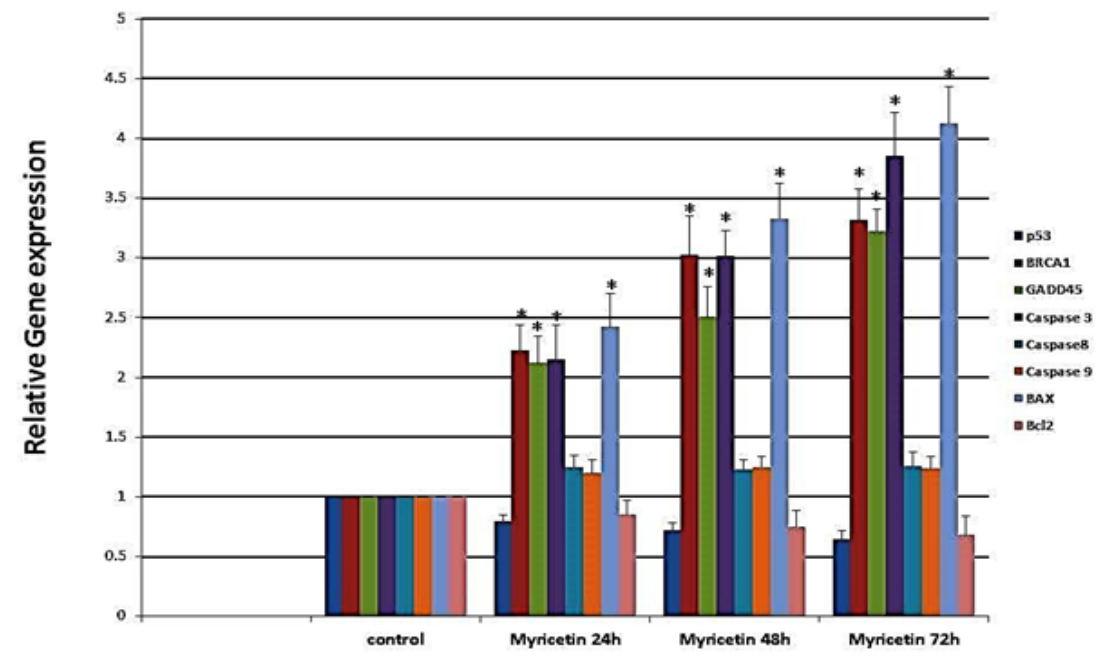

Figure 4. Real-Time PCR Gene Expression Analysis of T47-D Cells Treated by $46 \mu \mathrm{m}$ Myricetin for 24, 48, and 72 hrs. The expression of BRCA1, GADD45, Caspase-3, and BAX increased. However, the expression level of P53, caspase 8, caspase 9; and Bcl-2 did not show a noticeable change compared to control groups. Data are represented as mean \pm SD. ${ }^{*} \mathrm{p}<0.01$

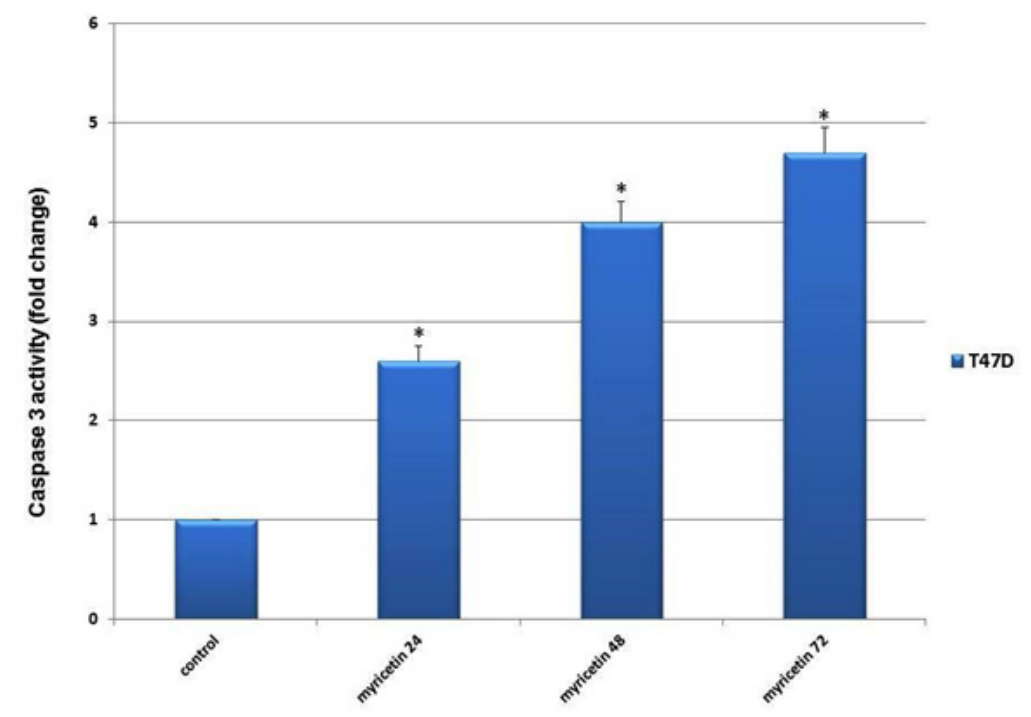

Figure 5. The Caspase-3 Activity in T47-D Breast Cancer Cells Plotted Against duration of Exposing Cells to $46 \mu \mathrm{m}$ Myricetin (24, 48 and $72 \mathrm{hrs}$ ). The Caspase-3 activity increased with time significantly compared to control group. The data is expressed as the percentage of cells that show a cytoplasmic fluorescence intensity greater than $450\left(Z^{\prime}=0.51\right)$.

gain carcinogenic properties that promote cancer cell invasiveness and metastasis (Tanaka et al., 2018).

In wild-type P53 breast cancer cell lines, it is suggested that flavonols induce apoptosis by regulating P53 gene expression. For instance, kaempferol induces apoptosis by up-regulation and phosphorylation of P53 ( Choi and Ahn, 2008).

According to the studies on liver cancer HepG2 and leukemia HL-60 cell lines, myricetin-induced apoptosis were reported to be due to induction of P53 expression and increased activities of Caspase 3 and 9 (Wang et al., 1999; Zhang et al., 2010; Zhang et al., 2013).

$B R C A 1$ is a tumor suppressor gene that its expression is usually reduced or absent in approximately $30 \%$ of sporadic cases (Esteller et al., 2000; Yang et al., 2001). $B R C A 1$ tumor suppressor gene induces apoptosis through both intrinsic and extrinsic pathways. However, BRCA1 acts through both P53-dependent and P53-independent pathways and JNK signaling pathway and GADD45 are involved in P53-independent pathway (Fabbro et al., 2004; Ostrakhovitch and Cherian, 2005; Choene et al., 2012; $\mathrm{Kim}, 2017)$. The result of the present study showed that the expression of BRCA1 and GADD45 increased following treatment with myricetin.

The precise molecular mechanism of myricetin has not been elucidated. In the previous studies, the apoptosis induced by myricetin has been declared to be Caspasedependent or Caspase-independent.

In the intrinsic pathway of apoptosis, increased ratio of BAX/Bcl-2 and activation of Caspase 9 are responsible in cell apoptosis. In the extrinsic pathway, activation of Caspase 8 and 10 initiate apoptosis (Nagata, 2000; Jiang 
et al., 2005; Singh et al., 2007).

The results of this study presented that the rate of cell apoptosis increased following the treatment of T47-D breast cancer cells with myricetin.

According to a report, myricetin induced apoptosis in human promyeloleukemic cell line HL-60 by increasing Caspase 3 and Caspase 9 activities and $\mathrm{B} A X / B c l 2$ expression (Wang et al., 1999). Another study on MCF-7 cell lines revealed that various concentrations of myricetin induce apoptosis in breast cancer cell lines. In addition, myricetin activated the expression of Bax protein and increased the activity of Caspase 3 (Jiao and Dong Zhang, 2016).

The promotion of the expression of caspase 3, and $B A X / B c l-2$ ratio elevated with time, while the expression of caspase 8 and caspase 9 remained unchanged during the experiment.

Finally, considering the presence of wild type $B R C A 1$ tumor suppressor gene in T47-D cell line and the incremental effects of myricetin on the expression of BRCA1, BAX, GADD45 and Caspase 3 genes, myricetin may exert its influencies in p53- mutated breast cancer cells by regulating GADD 45 and $B R C 1$. In conclusion, using myricetin could be suggested as a complementary approach in treatment of breast cancer with P53 mutations.

\section{References}

Ahmadian S, Barar J, Saei AA, Fakhree MA, Omidi Y (2009). Cellular toxicity of nanogenomedicine in MCF-7 cell line: MTT assay. J Vis Exp, 26, 1191.

Ahn DS, Lee HJ, Hwang J, et al (2018). Lambertianic acid sensitizes non-small cell lung cancers to TRAIL-induced apoptosis via inhibition of XIAP/NF-êB and activation of caspases and death receptor 4. Int J Mol Sci, 5, 1476.

Avila MA, Velasco JA, Cansado J, Notario V (1994). Quercetin mediates the down-regulation of mutant p53 in the human breast cancer cell line MDA-MB468. Cancer Res, 54, 2424-8.

Baur JA, Sinclair DA (2006). Therapeutic potential of resveratrol: the in vivo evidence. Nat Rev Drug Discov, 5, 493-506.

Boulton SJ (2006). Cellular functions of the BRCA tumoursuppressor proteins. Biochem Soc Trans, 34, 633-45.

Choene M, Mthembu N, Dlamini Z, et al (2012). Breast cancer: Small molecules targeting apoptosis, a prospective approach to safe scientific success. Adv Biosci Biotechnol, 3, 833-44.

Choi EJ, Ahn WS (2008). Kaempferol induced the apoptosis via cell cycle arrest in human breast cancer MDA-MB-453 cells. Nutr Res Pract Winter, 2, 322-5.

Dagdemir A, Durif J, Ngollo M, Bignon YJ, Bernard-Gallon D (2013). Histone lysine trimethylation or acetylation can be modulated by phytoestrogen, estrogen or anti-HDAC in breast cancer cell lines. Epigenomics, 5, 51-63.

Dashwood RH (2007). Frontiers in polyphenols and cancer prevention. J Nutr, 137, 267-9.

Erdman jr JW, Balentine D, Arab L, et al (2007). Flavonoids and heart: Proceedings of the ILSI North America Flavonoids Workshop, May 31June, 2006, Washington, DC. J Nutr, 137, 718-37.

Esteller M, Silva JM, Dominguez G, et al (2000). Promoter hypermethylation and BRCA1 inactivation in sporadic breast and ovarian tumors. J Natl Cancer Inst, 92, 564-9.

Fabbro M, Schuechner, S, Au WWY, Henderson BR (2004). BARD1 regulates BRCA1 apoptotic function by a mechanism involving nuclear retention. Exp Cell Res, 298, 661-73.

Gilbert ER, Liu D (2010). Flavonoids influence epigeneticmodifying enzyme activity: structure - function relationships and the therapeutic potential for cancer. Curr Med Chem, 17, 1756-68.

Harkin DP, Bean JM, Miklos D, et al (1999). Induction of GADD45 and JNK/SAPK-dependent apoptosis following inducible expression of BRCA1. Cell, 97, 575-86

He Y, Zhu Q, Chen M, et al (2016). The changing 50\% inhibitory concentration (IC50) of cisplatin: a pilot study on the artifacts of the MTT assay and the precise measurement of densitydependent chemoresistance in ovarian cancer. Oncotarget, 7, 70803-21.

Holliday DL, Speirs V (2011). Choosing the right cell line for breast cancer research. Breast Cancer Res, 13, 215.

Hollstein M, Sidransky D, Vogelstein B, Harris CC (1991). p53 mutations in human cancers. Science, 253, 49-53.

Jiang B, Xiao W, Shi Y, Liu M, Xiao X (2005). Heat shock pretreatment inhibited the release of Smac/DIABLO from mitochondria and apoptosis induced by hydrogen peroxide in cardiomyocytes and $\mathrm{C} 2 \mathrm{C} 12$ myogenic cells. Cell Stress Chaperones, 10, 25262.

Jiao D, Dong Zhang X (2016). Myricetin suppresses p21-activated kinase 1 in human breast cancer MCF-7 cells through downstream signaling of the â-catenin pathway. Oncol $R$ 342 Eports, 36, 342-8

Kim GD (2017). Myricetin inhibits angiogenesis by inducing apoptosis and suppressing PI3K/Akt/mTOR signaling in endothelial cells. J Cancer Prev, 22, 219-27

Kim ME, Ha TK, Yoon JH, Lee JS (2014). Myricetin induces cell death of human colon cancer cells via BAX/BCL2dependent pathway. Anticancer Res, 34, 701-6.

Lee E-YHP, Muller W-J (2010). Oncogenes and Tumor Suppressor Genes. Harbor Perspect Biol, 2, a003236.

Lee WH (1989). The molecular basis of cancer suppression by the retinoblastoma gene. Princess Takamatsu Symp, 20, 159-70.

Lim LY, Vidnovic N, Ellisen LW, Leong CO (2009). Mutant p53 mediates survival of breast cancer cells. Br J Cancer, 101, 1606-12.

Li Y, Ding Y (2012). Minireview: Therapeutic potential of myricetin in diabetes mellitus. Food Sci Hum Wellness, 1, 19-25.

Martínez-Pérez C, Ward C, Turnbull AK, et al, (2016). Antitumour activity of the novel flavonoid Oncamex in preclinical breast cancer models. Br J Cancer, 114, 905-16.

Nagata S (2000). Apoptotic DNA fragmentation. Exp Cell Res, 256, $12-8$.

Ostrakhovitch EA, Cherian MG (2005). Role of p53 and reactive oxygen species in apoptotic response to copper and zinc in epithelial breast cancer cells. Apoptosis, 10, 111-1.

Park JB, Lee JK, Park SJ, Kim KW, Riew KD (2005). Mitochondrial involvement in fas mediated apoptosis of human lumbar disc cells. J Bone Joint Surg Am, 87, 1338-42.

Perera RM, Bardeesy N (2012). On oncogenes and tumor suppressor genes in the mammary gland. Cold Spring Harb Perspect Biol, 4, 1-3.

Phillips PA, Sangwan V, Borja-Cacho D, et al (2011). Myricetin induces pancreatic cancer cell death via the induction of apoptosis and inhibition of the phosphatidylinositol 3-kinase (PI3K) signaling pathway. Cancer Lett, 308, 181-8.

Ponder KG, Boise LH (2019). The prodomain of caspase-3 regulates its own removal and caspase activation. Cell Death Discov, 5.

Rice JC, Ozcelik H, Maxeiner P, Andrulis L, Futscher BW (2000). Methylation of the BRCA1 promoter is associated 
with decreased BRCA1 mRNA levels in clinical breast cancer specimens. Carcinogenesis, 21, 1761-5.

Saluzzo J, Hallman KM, Aleck K, et al, (2016). The regulation of tumor suppressor protein, p53, and estrogen receptor $(\mathrm{ER} \alpha)$ by resveratrol in breast cancer cells. Genes Cancer, 7, 414-25.

Schutte B, Nuydens R, Geerts H, Ramaekers F (1998). Annexin $\mathrm{V}$ binding assay as a tool to measure apoptosis in differentiated neuronal cells. J Neurosci Methods, 86, 63-9.

Shin JC, Jung HY, Harikishore A, et al (2013). The flavonoid myricetin reduces nocturnal melatonin levels in the blood through the inhibition of serotonin $\mathrm{N}$-acetyltransferase. Biochem Biophys Res Co, 440, 312-6.

Shiomi K, Kuriyama I, Yoshida H and Mizushina, Y (2013). Inhibitory effects of myricetin on mammalian DNA polymerase, topoisomerase and human cancer cell proliferation. Food Chem, 139, 910-18.

Singh M, Sharma H, Singh N (2007). Hydrogen peroxide induces apoptosis in HeLa cells through mitochondrial pathway. Mitochondrion, 7, 36773.

Takagaki N, Sowa Y, Oki T, et al (2005). Apigenin induces cell cycle arrest and p21/WAF1 expression in a p53-independent pathway. Int J Oncol, 26, 185-9.

Weiss MB, Vitolo MI, Mohseni M, et al (2010). Deletion of p53 in human mammary epithelial cells causes chromosomal instability and altered therapeutic response. Oncogene, 29, 4715-24.

Tanaka N, Zhao M, Tang L, et al (2018). Gain-of-function mutant p53 promotes the oncogenic potential of head and neck squamous cell carcinoma cells by targeting the transcription factors FOXO3a and FOXM. Oncogene, 37, 191-202.

Wang IK, Lin-Shiau SY, Lin JK (1999). Induction of apoptosis by apigenin and related flavonoids through cytochrome $\mathrm{c}$ release and activation of caspase- 9 and caspase- 3 in leukaemia HL-60 cells. Eur J Cancer Oct, 35, 1517-25.

Weng CJ, Yen GC (2012). Flavonoids, a ubiquitous dietary phenolic subclass, exert extensive in vitro anti-invasive and in vivo anti-metastatic activities. Cancer Metastasis Rev, 31, 323-51.

Wu J, Wang YS, Yang XY, et al (2012). Graphene oxide used as a carrier for adriamycin can reverse drug resistance in breast cancer cells. Nanotechnology, 23, 355101

Yang Q, Sakurai T, Mori I, et al (2001). Prognostic significance of BRCA1 expression in Japanese sporadic breast carcinomas. Cancer, 92, 54-60.

Zang W, Wang T, Wang Y, et al (2014). Myricetin exerts anti-proliferative, antiinvasive, and pro-apoptotic effects on esophageal carcinoma EC9706 and KYSE30 cells via RSK2. Tumour Biol, 35, 1258392.

Zhang XH, Chen SY, Tang L, et al (2013). Myricetin induces apoptosis in HepG2 cells through Akt/p70S6K/bad signaling and mitochondrial apoptotic pathway. Anticancer Agents Med Chem, 13, 1575-81.

Zhang X, Ling Y, Yu H, Ji Y (2010). Studies on mechanism of myricetin-induced apoptosis in human hepatocellular carcinoma HepG-2 cells. Zhongguo Zhongyao Zazhi, 35, 1046-50.

Zheng A-W, Chen Y-Q, Zhao L-Q, Feng J-G (2017). Myricetin induces apoptosis and enhances chemosensitivity in ovarian cancer cells. Oncol Lett, 13, 4974-78.

This work is licensed under a Creative Commons AttributionNon Commercial 4.0 International License. 